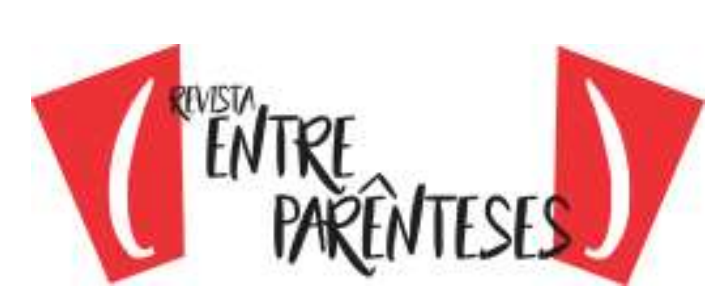

ISSN 2238-4502

\title{
A PRESENÇA DO TEXTO EM SALA DE AULA: UMA ANÁLISE DA BASE NACIONAL COMUM CURRICULAR NA PERSPECTIVA DA LINGUÍSTICA TEXTUAL
}

\author{
Sammya Santos Araújo \\ Universidade do Porto \\ (sammyaletras@hotmail.com) \\ Lya Oliveira da Silva Souza Parente \\ Universidade Estadual do Ceará \\ (lya.loss@gmail.com)
}

\begin{abstract}
Resumo
0 presente artigo busca refletir, à luz da Linguística Textual, sobre os pressupostos da Base Nacional Comum Curricular (BNCC) no componente Língua Portuguesa. Tentamos compreender quais perspectivas este documento normativo sugere para a abordagem do texto no Ensino Fundamental. Metodologicamente, realizamos uma análise exploratório-descritiva das competências e habilidades específicas que demandam a utilização do texto no processo de ensino e aprendizagem. Compreendemos que a BNCC ressalta o texto como seu objeto de estudo a partir das perspectivas enunciativo-discursivas, de modo que relaciona os textos a seus contextos de produção e o desenvolvimento de habilidades ao uso significativo da linguagem.
\end{abstract}

Palavras-chave: Texto. Linguística de texto. Ensino. BNCC.

DOI: https://doi.org/10.32988/rep.v10n1.1279

Dossiê "Possibilidades de trabalho com a Língua Portuguesa"

\begin{tabular}{|l|l|l|l|} 
Revista (Entre Parênteses) & Alfenas, MG & V.10 & n.
\end{tabular}

Departamento de Letras - Instituto de Ciências Humanas e Letras

Rua Gabriel Monteiro da Silva, 700 - Alfenas/MG - CEP 317131-001 - Brasil

https://publicacoes.unifal-mg.edu.br/revistas/index.php/entreparenteses/about 


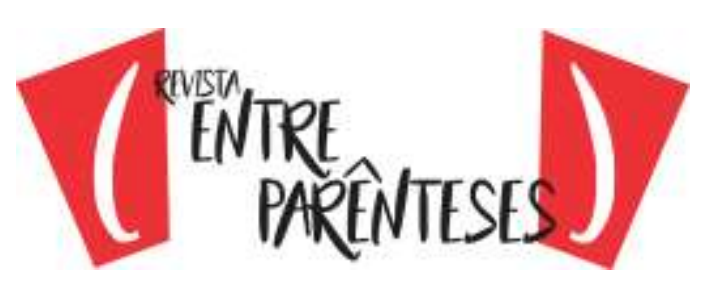

ISSN 2238-4502

\section{Sammya Santos Araújo}

Universidade do Porto

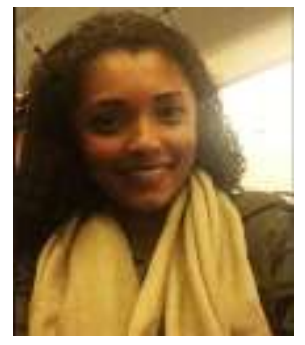

\section{http://lattes.cnpq.br/9778689245007110}

https://orcid.org/0000-0003-2548-6206

http://dgp.cnpq.br/dgp/espelhogrupo/7754743998565399

https://www.instagram.com/gpleer.gpleer/

https://sigarra.up.pt/flup/pt/cur_geral.cur_view?pv_curso_id=5921

DOI: https://doi.org/10.32988/rep.v10n1.1279

Dossiê "Possibilidades de trabalho com a Língua Portuguesa"

V. 10

n. 1

$1-22$

e021001


ISSN 2238-4502

\section{Lya Oliveira da Silva Souza Parente}

Universidade Estadual do Ceará
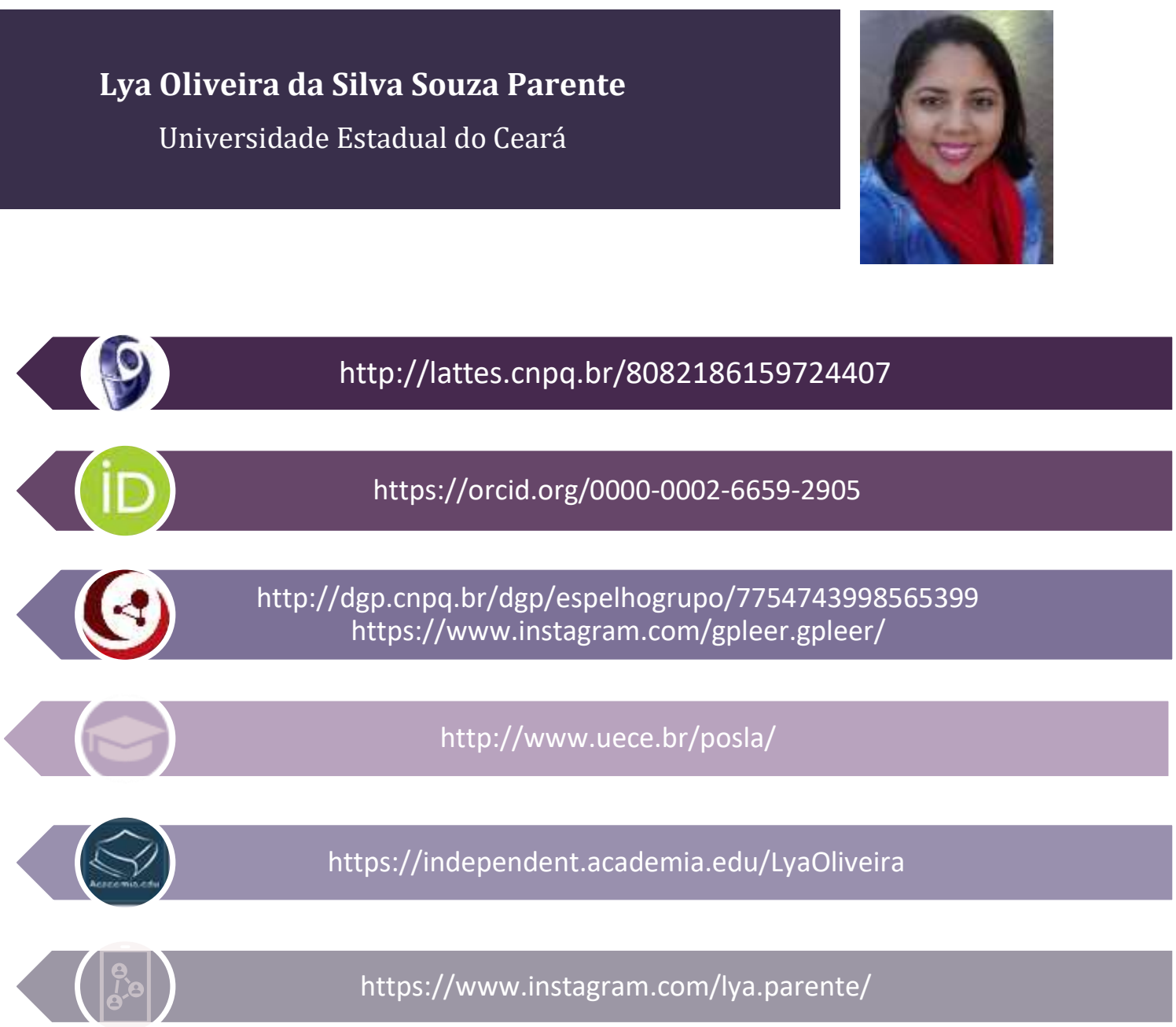

DOI: https://doi.org/10.32988/rep.v10n1.1279

Dossiê "Possibilidades de trabalho com a Língua Portuguesa"

V. 10

n. 1

$1-22$

e021001




\title{
(")
}

ISSN 2238-4502

\section{A PRESENÇA DO TEXTO EM SALA DE AULA: UMA ANÁLISE DA BASE NACIONAL COMUM CURRICULAR NA PERSPECTIVA DA LINGUÍSTICA TEXTUAL}

\author{
Sammya Santos Araújo ${ }^{1}$ \\ Universidade do Porto \\ (sammyaletras@hotmail.com) \\ Lya Oliveira da Silva Souza Parente ${ }^{2}$ \\ Universidade Estadual do Ceará \\ (lya.loss@gmail.com)
}

\section{Introdução}

A Base Nacional Comum Curricular (BNCC), atualmente, motiva muitas preocupações, discussões e estudos por parte do corpo pedagógico e dos profissionais da área de Linguagens e Códigos. Isso ocorre tendo em vista o processo de implantação deste documento, que será base para o Ensino Básico de todas as instituições de educação brasileira.

Nesse contexto, como professoras e pesquisadoras, percebemos que as atuais práticas pedagógicas brasileiras afluem para a utilização de textos dos mais variados gêneros possíveis em sala de aula, principalmente nas aulas de Língua Portuguesa, em que se priorizam as práticas de leitura e de produção textual, dando relevância aos processos da contextualização. Entretanto, sempre foi assim?

O espaço do texto na sala de aula, por muito tempo, ficou relegado ao trabalho com análise linguística que, no ensino tradicional, tomava a estrutura da oração e do período como unidade de estudo. A partir da década de 1980, em contrapartida a essa maneira de ensino da Língua Portuguesa, começaram a despontar propostas de trabalho que tomaram o texto como unidade de estudo essencial tanto em língua materna como em língua estrangeira (SANTOS,

\footnotetext{
1 Doutoranda em Ciências da Linguagem pela Universidade do Porto, da Faculdade de Letras (FLUP). Porto, Portugal.

2 Doutoranda e mestra pelo Programa de Pós-graduação em Linguística Aplicada da Universidade Estadual do Ceará (UECE). Fortaleza-CE, Brasil.
}

DOI: https://doi.org/10.32988/rep.v10n1.1279

Dossiê "Possibilidades de trabalho com a Língua Portuguesa"

\begin{tabular}{|l|l|l|l|l|l|l|}
\hline Revista (Entre Parênteses) & Alfenas, MG & V.10 & n. 1 & $1-22$ & e021001 & 2021 \\
\hline
\end{tabular}




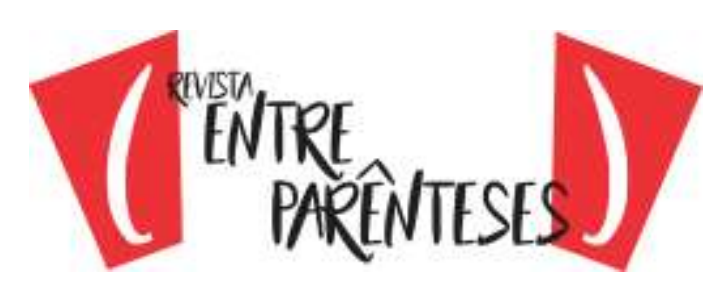

ISSN 2238-4502

2007). Vê-se, pois, que o texto passa a ser o foco de estudos dessa área linguística e a ser visto como unidade básica de interação verbal.

Para Koch (2004), a Linguística do Texto tem como objeto de investigação não mais a palavra ou frase isolada, mas o texto, que é considerada a unidade básica de manifestação da linguagem, pois o homem se comunica por meio de textos. Além disso, existem diversos fenômenos linguísticos que só podem ser explicados no interior de um texto. Ademais, a autora defende que texto é muito mais que a simples soma das frases (e palavras) que o compõem: a diferença entre frase e texto não é meramente de ordem quantitativa, e sim de ordem qualitativa.

Buscando compreender melhor onde situar o texto nos estudos linguísticos e em sala de aula, trazemos neste artigo uma discussão atual sobre a Base Nacional Curricular Comum, documento oficial que está sendo implementado em todas as escolas brasileiras e que reúne "o conjunto orgânico e progressivo de aprendizagens essenciais que todos os alunos devem desenvolver ao longo das etapas e modalidades da Educação Básica para cada série da educação básica" (BRASIL, 2018, p. 7). Trata-se de orientações sobre o que seria indispensável na educação de toda criança e todo adolescente brasileiro, além de constituir uma forma de nortear as propostas curriculares de escolas públicas e privadas.

Devido à complexidade desse documento normativo, detivemo-nos na análise do componente Língua Portuguesa do Ensino Fundamental, especificamente nas abordagens para a utilização do texto no cotidiano escolar. Para tanto, desenvolvemos uma discussão teórica sobre algumas definições e propriedades do texto para a Linguística de Texto e dos gêneros textuais, que nos permitiram a análise da BNCC e, por fim, apresentamos as considerações finais deste trabalho.

\section{0 texto e a Linguística de Texto}

Ao longo dos nossos estudos, percebemos a infinidade de definições sobre o que seria o texto. No decorrer deste artigo, serão apresentados alguns conceitos de teóricos que consideramos importantes para a compreensão desse fenômeno linguístico e social, para que assim possamos realizar a análise da Base Nacional Comum Curricular (BNCC) em Língua Portuguesa. Porém, antes de nos aprofundarmos neste assunto e mostrarmos um panorama de significação de texto, reconhecemos que a língua não serve apenas para representar ideias ${ }^{3}$. Conforme Mondada e Dubois (2003), a língua não é um espelho da realidade, de modo que não

\footnotetext{
${ }^{3}$ Existem algumas concepções de língua que pontuamos acima e devemos esclarecer melhor. Segundo Marcuschi (2008), na visão formalista, a língua é um sistema de regras autônomo diante das condições de produção. Na teoria da comunicação, a língua é um instrumento que transmite informações. Já pelo cognitivismo, a língua é um ato criação e expressão do pensamento. Aqui, adotamos a língua em uma perspectiva sociointeracionista, que relaciona os aspectos históricos e discursivos.
}

DOI: https://doi.org/10.32988/rep.v10n1.1279

Dossiê "Possibilidades de trabalho com a Língua Portuguesa"

\begin{tabular}{|c|c|c|c|c|c|c|} 
Revista (Entre Parênteses) & Alfenas, MG & V.10 & n. 1 & $1-22$ & e021001 & 2021 \\
\hline
\end{tabular}




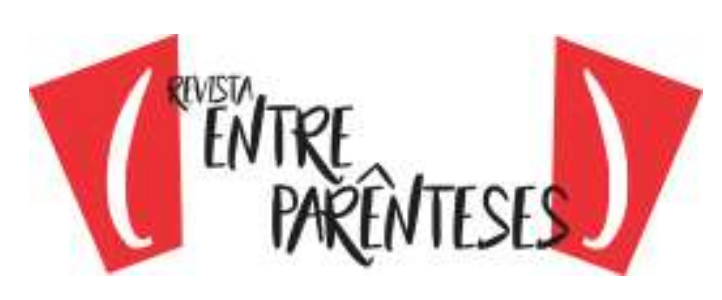

ISSN 2238-4502

apenas informa, mas também insere os indivíduos em contextos sócio-históricos, permitindoos que se entendam.

Essa conceituação relaciona-se com a ideia de interação dialógica exposta por Bakhtin (2003), uma vez que a língua circunscreve a concepção de texto, sem os quais, consequentemente, não podemos efetivar a interação verbal. Vemos aqui, portanto, o texto como uma ação linguística e social, logo, nesse sentido, funciona como um evento dialógico de interação entre sujeitos sociais. Dessa forma, ainda nessa perspectiva, conforme lembra Brait (2016), o texto é considerado:

[...] uma dimensão linguística atualizada por um sujeito coletivo ou individual, que se caracteriza como enunciado concreto, situado, pertencente a um contexto, a uma cultura, em diálogo com interlocutores presentes, passados e futuros. É justamente essa dimensão complexa de texto que impede seu enfrentamento unicamente pela perspectiva linguística, embora essa não possa ser descartada ${ }^{4}$ (BAKHTIN, 2003, p. 16).

Compreendermos, a partir dessa citação, que o texto ganha consistência ligando-se às situações que estão para além da materialidade linguística, pois perpassam valores históricos, culturais e sociais, o que discutiremos ao longo de nosso trabalho. 0 texto só tem vida quando interage com esses elementos, e sua construção é feita por sujeitos que apresentam uma bagagem cognitiva, sociocultural, histórica e interacional. Isto posto, para que ocorra a compreensão do texto, é necessário que o leitor mobilize um vasto número de conhecimentos diversos, já que a superfície material do texto não revela todos os seus sentidos, haja vista ser preciso identificar o intertexto, compreender a sua função no texto, saber qual é o tipo gênero textual e conectar o texto ao conhecimento de mundo.

Para Marcuschi (2008), texto é o resultado de uma ação linguística cujos limites são em geral definidos por seus vínculos com o mundo no qual ele surge e funciona, não podendo ser resumidamente considerado uma extensão da frase, mas como um tecido estruturado, uma entidade significativa, uma entidade de comunicação e um artefato sócio-histórico. Assim, de certo modo, afirma-se que o texto é uma (re)construção do mundo e refrata o mundo na medida em que o reordena e reconstrói. Mas, o que seria "refratar"? Nas palavras de Faraco (2009):

\footnotetext{
${ }^{4}$ Ao longo do nosso estudo, compreendemos que a teoria dialógica que emerge da obra de Bakhtin e seu Círculo ocupa um lugar de destaque nas definições e ampliações do conceito de texto. Para Koch e Elias (2010), essa concepção da língua torna o texto o lugar da interação de sujeitos constituídos social, cultural e historicamente. Marcuschi fala ainda que Bakhtin representa uma espécie de bom-senso teórico em relação à concepção da linguagem. (MARCUSCHI, 2008).
}

DOI: https://doi.org/10.32988/rep.v10n1.1279

Dossiê "Possibilidades de trabalho com a Língua Portuguesa"

\begin{tabular}{|l|l|l|l|l|l|l|} 
Revista (Entre Parênteses) & Alfenas, MG & V.10 & n. 1 & $1-22$ & e021001 & 2021 \\
\hline
\end{tabular}




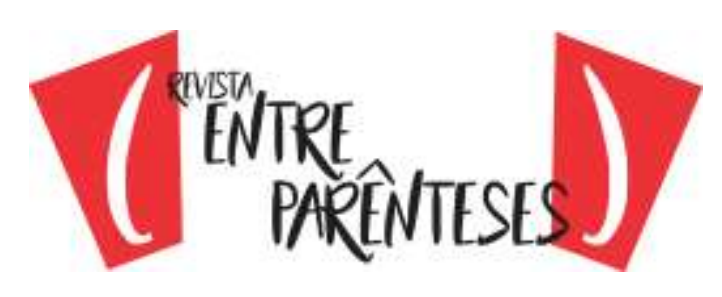

ISSN 2238-4502

E 'refratar' significa, aqui, que com nossos signos nós não somente descrevemos o mundo, mas construímos - na dinâmica da história e por decorrência do caráter sempre múltiplo e heterogêneo das experiências concretas dos grupos humanos - diversas interpretações (refrações) desse mundo. [...] Em outras palavras, a refração é o modo como se inscrevem nos signos a diversidade e as contradições das experiências históricas dos grupos humanos. Sendo essas experiências múltiplas e heterogêneas, os signos não podem ser unívocos (monossêmicos). A plurivocidade (o caráter multissêmico) é a condição de funcionamento dos signos nas sociedades humanas. (FARACO, 2009, p. 50-51).

A construção do mundo pelo texto, de acordo com o que foi dito anteriormente, não se manifesta apenas conforme o entendimento do uso comum dos conceitos, mas também baseados na nossa própria singularidade. Portanto, é necessária uma linha de estudo dentro da linguística que especifique e trate melhor as particularidades do texto.

A Linguística de Texto ou Linguística Textual, doravante LT, surgida em meados dos anos 60 do século XX, trata hoje tanto da produção quanto da compreensão de textos orais e escritos. Logo, a língua não se dá em unidades isoladas, mas sim em unidades de sentido chamadas texto (MARCUSCHI, 2008). Essa linguística assume uma importante função no ensino de língua, pois preocupa-se com a reflexão acerca do seu funcionamento nas mais diversas situações de produção na vida diária, ou seja, na concretização de interação verbal.

0 texto é a materialização da língua, como já compreendemos até aqui. Na comunicação, o todo significativo pode ser verbal e não verbal. Nas palavras de Koch (2014), a LT trata o texto como um ato de comunicação unificado em um complexo universo de ações humanas. Com isso, a teoria do texto está permeada por um viés interdisciplinar, visto que lança olhares para uma gama de fatores linguísticos, como o pragmático, o semântico, o lexical, o gramatical, isto é, elementos que complementam a estrutura e funcionalidade do objeto de estudo dessa corrente linguística.

Esta unidade comunicativa que é o texto obedece a um conjunto de critérios de textualização, esquematização e figuração. Beaugrande e Dressler (1981 apud BENTES; REZENDE, 2008, p. 28) postulam a textualidade como um princípio organizacional e comunicativo do texto. Se, como escrevem, "a questão mais urgente é como os textos funcionam na interação humana", o "status de texto" só é alcançado mediante a satisfação de sete critérios para seu funcionamento, que correspondem a: coesão, coerência, intencionalidade, informatividade, aceitabilidade, situacionalidade e intertextualidade. (BEAUGRANDE; DRESSLER, 1981 apud BENTES; REZENDE, 2008, p. 28).

A textualidade é construída com base nas interações, nos desdobramentos em outros textos e também na interpretação das relações texto-contexto que os participantes vão produzindo durante o processo comunicativo. Desde o momento em que textualizamos, compreendemos o texto e, com construímos conhecimento a partir dele.

DOI: https://doi.org/10.32988/rep.v10n1.1279

Dossiê "Possibilidades de trabalho com a Língua Portuguesa"

\begin{tabular}{|l|l|l|l|l|l|l} 
Revista (Entre Parênteses) & Alfenas, MG & V.10 & n. 1 & $1-22$ & e021001 & 2021 \\
\hline
\end{tabular}




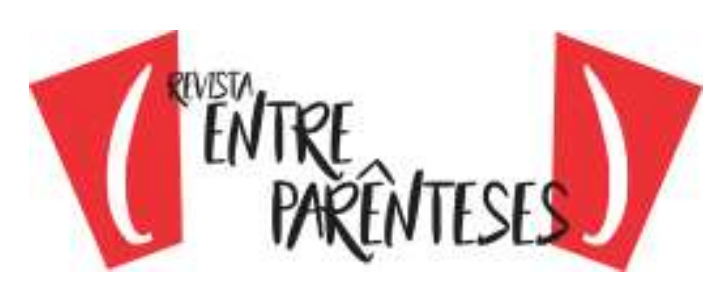

ISSN 2238-4502

De acordo com Hanks (2008), a textualidade, em termos gerais, é a qualidade de coerência e conectividade que caracteriza o texto. Essa conectividade engloba propriedades inerentes ao artefato textual, o que se refere às atividades interpretativas de uma comunidade de leitores/espectadores ou da combinação de ambas. Esse autor afirma que, mesmo que as propriedades formais e funcionais de signos complexos possam auxiliar no estabelecimento da textualidade, é a adequação entre a forma do signo e um contexto mais amplo que determina sua coerência em última instância.

Para Lopes (2005), tais critérios de textualidade devem ser lidos em uma perspectiva de definição prototípica da categoria, ou seja, são propriedades que caracterizam os membros mais centrais e mais representativos da categoria, podendo algumas delas estar ausentes nos exemplares mais periféricos. Marcuschi (2008) completa que não se pode dividir os aspectos da textualidade de forma tão estanque e categórica, uma vez que alguns critérios são redundantes e se recobrem. Portanto, compreendemos que os aspectos aliam a organização interna a uma função comunicativa do texto e não funcionam como leis linguísticas, pois a ausência de um critério não impede que haja um texto.

Assim, estudar o texto na perspectiva da LT é também estudar uma estrutura com objetivações e intenções definidas, dado que o falante aciona uma complexa rede de fatores ao produzi-lo de forma escrita ou falada. Marcuschi (2008) ressalta ainda que a LT é uma das áreas mais promissoras da linguística atual porque proporciona uma ampla investigação de seu objeto de estudo, cuja materialização se apresenta no nosso cotidiano por meio dos gêneros textuais. A seguir discutiremos sobre esta temática no trato sociointerativo da produção linguística.

\section{Gêneros textuais}

0 texto, na condição de estrutura dotada de sentido, está presente no cotidiano nas mais diversas formas, sendo importante, portanto, estudarmos suas especificidades na escola e em sala de aula. Dolz e Schneuwly (2004), assim como outros teóricos que tratam de texto/discurso, acreditam que é por meio dos textos que o ensino da Língua Portuguesa deve ser feito, por isso sugerem que o trabalho da língua precisa ser pautado nos diferentes gêneros textuais, sejam eles orais ou escritos. Segundo os autores, os gêneros são formas de funcionamento da língua e linguagem, sendo criados conforme as diferentes esferas da sociedade nas quais o indivíduo circula. Eles são produtos sociais bastante heterogêneos, o que possibilita infinitas construções durante a comunicação.

Conforme Bakhtin (2003), o uso da linguagem perpassa todas as atividades humanas relevantes, as quais são tão variadas que acarretam uma utilização extremamente diversificada da linguagem. Isso leva à multiplicidade e à infinidade de gêneros, uma vez que o somatório das atividades desenvolvidas numa sociedade é proporcional à quantidade de gêneros produzidos para atender a cada circunstância em seu respectivo contexto.

DOI: https://doi.org/10.32988/rep.v10n1.1279

Dossiê "Possibilidades de trabalho com a Língua Portuguesa"

\begin{tabular}{|l|l|l|l|l|l|l} 
Revista (Entre Parênteses) & Alfenas, MG & V.10 & n. 1 & $1-22$ & e021001 & 2021 \\
\hline
\end{tabular}




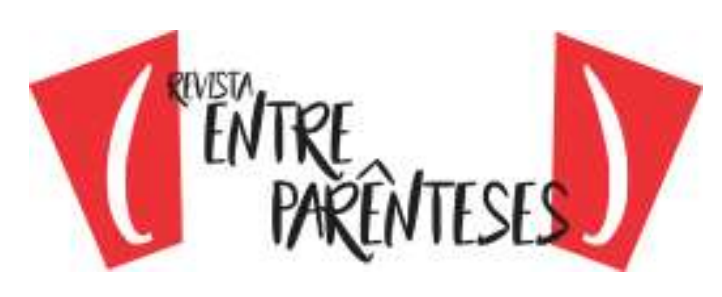

ISSN 2238-4502

Contudo, esse autor diz que os indivíduos dominam os gêneros antes mesmo de conhecerem a gramática. Sua apreensão se dá tal qual a do léxico e a da estrutura gramatical que compõem a língua materna de maneira espontânea, no convívio social, pois a socialização desde muito cedo (idade) é feita por intermédio dos gêneros do discurso. Para Bakhtin (2003), eles são imprescindíveis à comunicação humana.

0 autor ratifica esse posicionamento afirmando que, se não existissem os gêneros do discurso e se não os dominássemos, se tivéssemos de criá-los pela primeira vez no processo da fala, se tivéssemos de construir cada um de nossos enunciados, a comunicação verbal seria impossível (BAKHTIN, 2003). Sem dúvida, os gêneros desempenham um papel de grande relevância na vida dos indivíduos. Eles organizam a comunicação, tornando-a condizente com as circunstâncias, com a posição social e com o relacionamento dos interlocutores. Prova disso é sabermos empregá-los de forma adequada em diferentes e nos mais variados contextos.

As atividades sociais produzem uma extrema diversidade de gêneros, o que pode implicar dificuldades para assinalar seus traços comuns entre as atividades e os gêneros nelas produzidos. Dessa forma, ainda em Bakhtin (2003) e em suas valiosas contribuições, encontramos a distinção entre os gêneros primários e os secundários. Em linhas gerais, os gêneros primários constituem-se naqueles de uso cotidiano, diretamente relacionado ao contexto de produção. Já os secundários circunscrevem eventos culturais manifestados de maneira mais complexa, sobretudo por meio da escrita, tais como romances, discursos científicos e ideológicos, peças de teatro, dentre outros.

Como vimos, os gêneros textuais/discursivos estão sempre relacionados à prática discursiva ou às atividades sociais que realizamos. Além disso, apesar da enorme variedade de gêneros e de sua produção sistemática, eles são considerados aleatórios. Conforme Bakhtin (2003), os gêneros textuais/discursivos contêm uma estabilidade relativa, pois, apesar de possuir uma forma específica que os torna reconhecíveis, são suscetíveis a mudanças ao longo da vida. Esse atributo possibilita o surgimento de novos gêneros nas culturas, principalmente as digitais, em geral para atender a necessidades cotidianas de interação verbal.

Atualmente, o estudo dos gêneros textuais é considerado um campo fértil interdisciplinar, com atenção especial para a linguagem em funcionamento e para as atividades culturais e sociais, desde que não concebamos os gêneros como modelos estanques nem como estruturas rígidas, mas como formas culturais e cognitivas de ação social. Marcuschi (2008) nos mostra uma visão bem esclarecedora e didática sobre esse tema:

Os gêneros textuais são os textos que encontramos em nossa vida diária e que apresentam padrões sociocomunicativos característicos definidos por composições funcionais, objetivos enunciativos e estilos concretamente realizados na integração de forças históricas, sociais, institucionais e técnicas. Em contraposição aos tipos, os gêneros são entidades empíricas em situações comunicativas e se expressam em designações diversas, constituindo em princípio listagens abertas. (MARCUSCHI, 2008, p. 155).

DOI: https://doi.org/10.32988/rep.v10n1.1279

Dossiê "Possibilidades de trabalho com a Língua Portuguesa"

\begin{tabular}{|l|l|l|l|l|l|l} 
Revista (Entre Parênteses) & Alfenas, MG & V.10 & n. 1 & $1-22$ & e021001 & 2021 \\
\hline
\end{tabular}


Possibilitar o estudo dos mais diversos gêneros em sala de aula permite refletir e assimilar o uso da língua como prática social, além de pensar o ensino como lugar de práticas de linguagem e, a partir delas, compreendê-las. 0 intuito dessa compreensão não se resume a descrevê-las, mas ampliar as possibilidades de aplicação da língua nas inúmeras situações diárias, uma vez que o sujeito domina os gêneros textuais antes mesmo de entrar na escola. Ademais, esse mesmo indivíduo, como vimos, utiliza os gêneros textuais nas mais diversas instâncias comunicativas, percebendo o que é adequado ou inadequado às práticas sociais e a determinados contextos. Sem dúvida, é no contato com a variedade de gêneros do cotidiano receita médica, receita culinária, bula, carta, bilhete, propaganda, artigos científicos, avisos, dentre outros - que o falante desenvolve a sua capacidade metatextual (KOCH, 2002).

Ressaltamos que muitos desses gêneros são reconhecidos por pessoas que não detêm as habilidades de leitura e de escrita: carta, bilhete, telegrama, bula de remédio etc., enquanto muitos outros não podem ser reconhecidos ou elaborados sem a aquisição dessas habilidades: petição, escritura pública, ordem do dia etc. Isso ocorre porque, embora os gêneros estejam disponíveis no intertexto, a apropriação de alguns deles só ocorre no contexto escolar. Trata-se, muitas vezes, de gêneros mais elaborados, que necessitam da mediação do professor para serem produzidos. Daí ser o ensino de língua materna por meio dos gêneros textuais imprescindível ao desenvolvimento da capacidade linguístico-discursiva do aluno nas modalidades oral e escrita, de modo a possibilitá-lo interagir nas mais diversas instâncias sociais.

Nessa perspectiva, Antunes (2002) declara que o ensino de língua pautado nos gêneros textuais poderá favorecer o estudante em vários aspectos, dentre os quais ressalta: apreensão de fatos linguístico-comunicativos contextualizados; ampliação da competência linguístico-comunicativa referente à produção e à recepção de textos (orais e escritos) funcionais no âmbito social; compreensão da natureza do texto, de modo a perceber-lhes a adequação vocabular e sequencial; correlação entre os aspectos textuais e pragmáticos existentes no ato comunicativo; ampliação dos parâmetros linguísticos, de indicativos da realização linguística ideal. Essas habilidades, uma vez desenvolvidas, poderão favorecer o domínio linguístico-discursivo do aluno, de modo a levá-lo a interagir eficazmente no seu contexto sociocultural.

Diante do exposto, a seguir apresentamos nossa análise do componente de Língua Portuguesa presente na BNCC para Ensino Fundamental - Anos Finais: práticas de linguagem, objetos de conhecimento e habilidades.

4 Análise da BNCC em Língua Portuguesa

DOI: https://doi.org/10.32988/rep.v10n1.1279

Dossiê "Possibilidades de trabalho com a Língua Portuguesa"

\begin{tabular}{|l|l|l|l|l|l|l} 
Revista (Entre Parênteses) & Alfenas, MG & V.10 & n. 1 & $1-22$ & e021001 & 2021 \\
\hline
\end{tabular}




\section{(")}

ISSN 2238-4502

A Base Nacional Comum Curricular (BNCC), objeto da nossa análise à luz da Linguística de Texto, é um documento oficial que regulamenta quais são as aprendizagens essenciais a serem trabalhadas nas escolas brasileiras públicas e particulares ao longo das três etapas da Educação Básica, a qual, por sua vez, corresponde à Educação Infantil, ao Ensino Fundamental e ao Ensino Médio, garantindo um patamar comum de aprendizagens a todos os estudantes.

A base foi prevista no artigo 210 da Constituição Federal de 1988, e sua necessidade foi reiterada na Lei de Diretrizes e Bases da Educação Nacional (LDB), em 1996. Posteriormente, em 2014, o Plano Nacional de Educação (PNE) instituiu metas para a melhoria da Educação Básica, dentre as quais quatro tratavam sobre a BNCC. Esta centralização das orientações educacionais vem norteando não só a elaboração de currículos escolares das redes públicas e privadas, como também direciona atualmente a formação de professores, a produção de materiais didáticos, as pesquisas nos cursos de pós-graduação e os processos de seleção para a Educação Superior.

Em julho de 2015, a primeira versão da Base começou a ser produzida a partir da convocação de especialistas, professores e assessores. Entre outubro do mesmo ano e março de 2016, houve uma consulta pública dessa versão no site do Ministério da Educação (MEC). A terceira versão foi entregue ao Conselho Nacional de Educação em abril de 2017, tendo sido aprovada em novembro do mesmo ano e, em seguida, homologada pelo Ministério. Analisamos, portanto, a terceira versão ${ }^{5}$.

Todavia, a construção da base pode ter "sido tecida numa atmosfera completamente adversa, fruto de acordos políticos e de tecnologias universalizantes" (CORRÊA; MORGADO, 2018, p. 2). Além desse contexto, compreendemos que a BNCC reflete também as preocupações com os resultados das avaliações de larga escala alçados pelos alunos brasileiros.

Autores como Cunha e Lopes (2017) e Lugli et al. (2015) relatam que instituições acadêmicas adotam uma posição mais crítica, enquanto setores empresariais e governamentais apoiam a proposta. Em nossas leituras, reforçamos a importância de um olhar crítico e que contemple as diversidades locais do ensino brasileiro quando ocorrer sua implementação.

A BNCC abrange todas as etapas da Educação Básica como mencionamos, porém, nossa análise é um recorte do componente Língua Portuguesa voltada para o Ensino Fundamental - Anos Finais. Restringimos nosso objeto de análise, dado que, durante nossos estudos, observamos que, no Ensino Fundamental - Anos Iniciais, os componentes curriculares tematizam diversas práticas, considerando especialmente aquelas relativas às culturas infantis tradicionais e contemporâneas.

Nos Anos Iniciais, o processo de alfabetização ainda é o foco da ação pedagógica (nos dois primeiros anos), logo, este estudante ainda está ampliando suas possibilidades de

5 É possível acompanhar essa cronologia no site do Movimento pela Base. Disponível em: https://movimentopelabase.org.br/linha-do-tempo/. Acesso em: 10 jan. 2021.

DOI: https://doi.org/10.32988/rep.v10n1.1279

Dossiê "Possibilidades de trabalho com a Língua Portuguesa"

\begin{tabular}{|l|l|l|l|l|l|l|} 
Revista (Entre Parênteses) & Alfenas, MG & V. 10 & n. 1 & $1-22$ & e021001 & 2021 \\
\hline
\end{tabular}




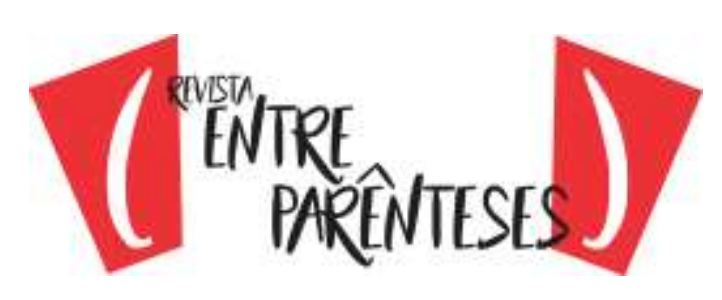

ISSN 2238-4502

construir conhecimentos nas diferentes áreas, devido à sua inserção na cultura letrada, e de participar com maior autonomia e protagonismo na vida social.

Já no Ensino Fundamental - Anos Finais, percebemos que as aprendizagens, nos componentes curriculares dessa área, ampliam as práticas de linguagem conquistadas no Ensino Fundamental - Anos Iniciais, incluindo a aprendizagem de Língua Inglesa. Nesse segmento, a diversificação dos contextos permite o aprofundamento de prática reflexiva e crítica do aluno, voltando mais para o uso do texto em sala de aula (BRASIL, 2018).

De modo geral, na área da linguagem, este documento busca tratar dos conhecimentos relativos à atuação dos sujeitos em práticas de linguagem, nos vários âmbitos da comunicação humana, desde as mais cotidianas às mais formais e elaboradas. Esses conhecimentos permitem estimular e ampliar recursos expressivos para construir sentidos com o outro em diferentes campos de atuação. Propiciam, ainda, compreender como o ser humano se constitui como sujeito e como age no mundo social em interações mediadas por palavras, imagens, sons, gestos e movimentos.

Primeiramente, quando se aborda o Ensino Fundamental - Anos Finais, alerta-se que os alunos possuem maiores desafios, pois existe a necessidade de se apropriarem das diferentes lógicas de organização dos conhecimentos por meio da especialização nos componentes curriculares, ampliando, assim, o repertório dos estudantes e fortalecendo sua autonomia para interagir criticamente em sociedade.

Ao tratar do componente Língua Portuguesa, a BNCC ressalta o texto como seu objeto de estudo por meio da abordagem nas "perspectivas enunciativo-discursivas" (BRASIL, 2018, p. 67). Nela, é possível relacionar os textos a seus contextos de produção, bem como o desenvolvimento de habilidades ao uso significativo da linguagem em atividades de leitura, escuta e produção de textos em várias mídias e semioses, conforme o seguinte trecho do documento:

Quadro 1 - A centralidade do texto como unidade de trabalho na BNCC

[...] o texto ganha centralidade na definição dos conteúdos, habilidades e objetivos, considerado a partir de seu pertencimento a um gênero discursivo que circula em diferentes esferas/campos sociais de atividade/comunicação/uso da linguagem. Os conhecimentos sobre os gêneros, sobre os textos, sobre a língua, sobre a norma-padrão, sobre as diferentes linguagens (semioses) devem ser mobilizados em favor do desenvolvimento das capacidades de leitura, produção e tratamento das linguagens, que, por sua vez, devem estar a serviço da ampliação das possibilidades de participação em práticas de diferentes esferas/ campos de atividades humanas.

Fonte: Brasil (2018, p. 67).

DOI: https://doi.org/10.32988/rep.v10n1.1279

Dossiê "Possibilidades de trabalho com a Língua Portuguesa"

\begin{tabular}{|l|l|l|l|l|l|l|} 
Revista (Entre Parênteses) & Alfenas, MG & V. 10 & n. 1 & $1-22$ & e021001 & 2021 \\
\hline
\end{tabular}




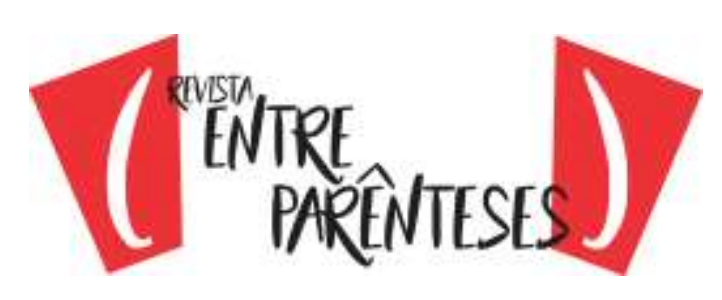

ISSN 2238-4502

Tal proposta assume a centralidade do texto como unidade de trabalho e as perspectivas enunciativo-discursivas na abordagem, de forma a sempre relacionar os textos a seus contextos de produção e o desenvolvimento de habilidades ao uso significativo da linguagem em atividades de leitura, escuta e produção de textos em várias mídias e semioses.

Essa abordagem enunciativo-discursiva sobre a linguagem tem em Bakhtin seu precursor, uma vez que ele a amplia ao considerá-la não como um privilégio do verbal, mas todas as manifestações que tenham a interferência humana constituem-se como linguagem, enunciado, texto (BAKHTIN, 2003). Logo, interessa compreender o processo de produção enunciativa e as estratégias inerentes a esse processo. Considera-se, portanto, a esfera social, o contexto imediato e o contexto mais amplo, que marcam a heterogeneidade dos sujeitos, os lugares e as posições sociais, historicamente construídos, e que atuam sobre as relações estabelecidas na interação dialógica, determinando as condições de produção verbal.

Especificando o que se deve ser trabalhado nos anos finais do Ensino Fundamental brasileiro, a BNCC sugere que se amplie o

[...] contato dos estudantes com gêneros textuais relacionados a vários campos de atuação e a várias disciplinas, partindo-se de práticas de linguagem já vivenciadas pelos jovens para a ampliação dessas práticas, em direção a novas experiências. (BRASIL, 2018, p. $\left.{ }^{\circ} 136\right)$.

Nota-se que o professor necessita valorizar as aprendizagens de gêneros já conhecidas pelo seu aluno, apresentar novos exemplares e ensiná-lo a utilizá-los em suas experiências em sociedade. 0 documento em análise demonstra ainda uma aproximação e uma preocupação com os estudantes nessa fase de ensino, na qual o uso das mídias digitais e das redes sociais é bem ativo para o trato dos gêneros, como percebemos nesse trecho:

Quadro 2 - 0 uso dos gêneros digitais

Para além dos gêneros, são consideradas práticas contemporâneas de curtir, comentar, redistribuir, publicar notícias, curar etc. e tematizadas questões polêmicas envolvendo as dinâmicas das redes sociais e os interesses que movem a esfera jornalística-midiática. A questão da confiabilidade da informação, da proliferação de fake news, da manipulação de fatos e opiniões tem destaque e muitas das habilidades se relacionam com a comparação e análise de notícias em diferentes fontes e mídias, com análise de sites e serviços checadores de notícias e com o exercício da curadoria, estando previsto o uso de ferramentas digitais de curadoria.

Fonte: Brasil (2018, p. 136).

DOI: https://doi.org/10.32988/rep.v10n1.1279

Dossiê "Possibilidades de trabalho com a Língua Portuguesa"

\begin{tabular}{|c|c|c|c|c|c|c|} 
Revista (Entre Parênteses) & Alfenas, MG & V.10 & n. 1 & $1-22$ & e021001 & 2021 \\
\hline
\end{tabular}




\section{(")}

ISSN 2238-4502

Aqui, nesse preâmbulo, merece destaque a clara referência ao ensino de gêneros digitais e multimidiáticos, uma vez que os novos meios de comunicação e as novas tecnologias possibilitam novas formas de interação. Nesse sentido, é importante destacar que Rojo e Barbosa (2015) apontam para o fato de que gêneros discursivos podem se modificar para satisfazer as necessidades de diversas atividades humanas em ambiente virtual, sendo importante que a escola considere essas constantes mudanças.

Ao longo do documento que analisamos, percebemos o enfático posicionamento pelo estudo dos gêneros textuais e suas respectivas implicações para o desenvolvimento de certas habilidades. Assim, a BNCC reforça a importância dos estudos da LT para um ensino de língua portuguesa pautado na interação entre os sujeitos e na construção de sentidos do texto a partir de várias formas de textualização.

No documento em análise, existe também um certo destaque para o uso dos gêneros jornalísticos, área na qual se incluem os publicitários, prevendo o tratamento de anúncios publicitários e propaganda impressa, nas diferentes mídias. Tão grande é o enfoque nos gêneros que existe um campo específico de trabalho na BNCC denominado "Campo JornalísticoMidiático". A seguir, selecionamos as habilidades que o documento solicita que sejam utilizadas em sala de aula:

\section{Quadro 3 - Habilidades trabalhadas no Campo Jornalístico-Midiático}

Vários são os gêneros possíveis de serem contemplados em atividades de leitura e produção de textos para além dos já trabalhados nos anos iniciais do ensino fundamental (notícia, álbum noticioso, carta de leitor, entrevista etc.): reportagem, reportagem multimidiática, fotorreportagem, foto-denúncia, artigo de opinião, editorial, resenha crítica, crônica, comentário, debate, vlog noticioso, vlog cultural, meme, charge, charge digital, political remix, anúncio publicitário, propaganda, jingle, spot, dentre outros. A referência geral é que, em cada ano, contemplem-se gêneros que lidem com informação, opinião e apreciação, gêneros mais típicos dos letramentos da letra e do impresso e gêneros multissemióticos e hipermidiáticos, próprios da cultura digital e das culturas juvenis.

Fonte: Brasil (2018, p. 141).

No geral, consideramos que a BNCC escolheu acertadamente trabalhar com as práticas de linguagem. No fragmento acima, por exemplo, percebe-se o reforço ao trabalho do gênero no discurso do âmbito público, como os textos jornalísticos e publicitários.

Entretanto, sentimos falta de uma focalização nos gêneros cotidianos do universo do estudante em sala de aula. Rojo (1999) ressalta que, em sua esfera, a escola desenvolve

DOI: https://doi.org/10.32988/rep.v10n1.1279

Dossiê "Possibilidades de trabalho com a Língua Portuguesa"

\begin{tabular}{|c|c|c|c|c|c|c|} 
Revista (Entre Parênteses) & Alfenas, MG & V.10 & n. 1 & $1-22$ & e021001 & 2021 \\
\hline
\end{tabular}




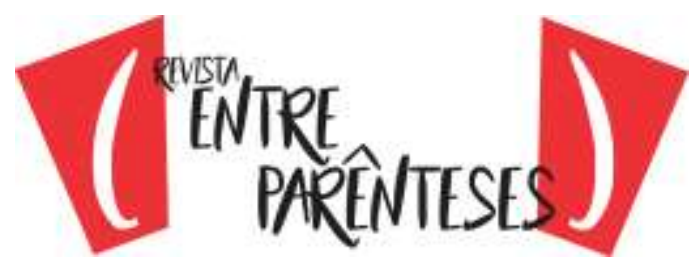

ISSN 2238-4502

gêneros textuais que podem ser analisados sob os aspectos didáticos e pedagógicos. No que concerne ao aspecto didático, são produzidos gêneros escolares, que fazem parte do cotidiano da instituição, que são responsáveis pelo desenvolvimento das atividades didático-pedagógicas e que dão dinamicidade à escola (declarações, regulamentos, explicações, exposições, instruções).

No bojo do aspecto didático, encontramos os gêneros escolares, os quais Rojo denomina escolarizados, como os artigos de opiniões, resenhas, textos dissertativosargumentativos, e que são encontrados, essencialmente, nas atividades de produção escrita. Eles são objeto de ensino, possibilitando o desenvolvimento da competência comunicativa do indivíduo para aquela atividade escolar, sem levar em consideração as demais práticas sociais reais e os gêneros nelas produzidos.

Nesse sentido, retomamos os estudos de Schneuwly e Dolz (2004) ao afirmar que o gênero não é só instrumento de comunicação, mas também objeto de ensino e aprendizagem. Segundo os autores, o aluno fica numa posição de "como se", falseada, de certa maneira, já que o gênero está sendo usado como pretexto para a aprendizagem. Logo, entendemos os gêneros escolares ou escolarizados como gêneros de texto produzidos em contexto escolar, ligados a atividades sociais e linguísticas delimitadas pelo espaço institucional escolar. Para ilustrar quais gêneros escolares poderiam ter sido contemplados nos Anos Finais do Ensino Fundamental da BNCC, citamos a narração escolar, a descrição escolar e a dissertação, que foram exemplificados por Koch (2002).

Outro ponto que destacamos, no documento em análise, é a defesa do desenvolvimento de habilidades de revisão textual para o aprimoramento da escrita:

Quadro 4 - Habilidades de revisão/edição de texto informativo e opinativo

Revisar/editar o texto produzido - notícia, reportagem, resenha, artigo de opinião, dentre outros -, tendo em vista sua adequação ao contexto de produção, a mídia em questão, características do gênero, aspectos relativos à textualidade, a relação entre as diferentes semioses, a formatação e uso adequado das ferramentas de edição (de texto, foto, áudio e vídeo, dependendo do caso) e adequação à norma culta.

Fonte: Brasil (2018, p. 143).

Revisar é uma etapa fundamental no processo de produção textual. Para Brandão (2007), a revisão de um texto é a oportunidade de refletir, de pensar sobre o que foi ou está sendo escrito e encontrar meios para melhor dizer o que se quer expressar, reelaborando e reescrevendo o já escrito. Portanto, é preciso que aquele que escreve se desloque entre os

DOI: https://doi.org/10.32988/rep.v10n1.1279

Dossiê "Possibilidades de trabalho com a Língua Portuguesa"

\begin{tabular}{|l|c|c|c|c|c|c|}
\hline Revista (Entre Parênteses) & Alfenas, MG & V. 10 & n. 1 & $1-22$ & e021001 & 2021 \\
\hline
\end{tabular}




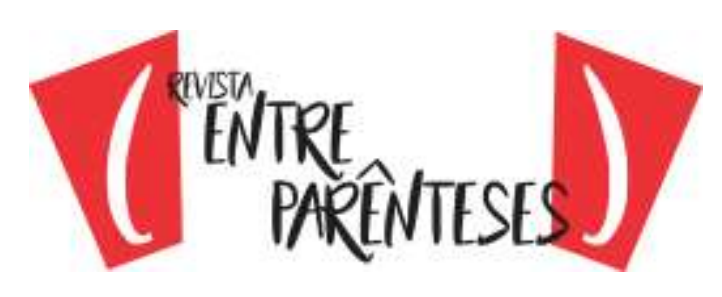

ISSN 2238-4502

papéis de escritor e possíveis leitores/interlocutores de seu texto, refletindo se seu escrito atende às suas intenções, bem como se está adequado à situação comunicativa em que ele se insere. Seria um grande aprimoramento se a revisão textual fosse também um trabalho de parceria entre professor e aluno, baseado no pressuposto de que o texto não é finalizado na primeira versão. No processo de revisão, ao se colocar tanto no papel de escritor como no papel de leitor, o aluno poderá então perceber quais elementos prejudicam o entendimento e a forma do texto.

Além dos gêneros que citamos, indicados na BNCC para serem trabalhados em sala de aula, ganham destaque nesse documento os gêneros legais e normativos - abrindo-se espaço para aqueles que regulam a convivência em sociedade, como regimentos, estatutos e códigos, conforme verificamos a seguir:

Quadro 5 - Gêneros normativos e legais

Analisar a forma composicional de textos pertencentes a gêneros normativos/jurídicos e a gêneros da esfera política, tais como propostas, programas políticos (posicionamento quanto a diferentes ações a serem propostas, objetivos, ações previstas etc.), propaganda política (propostas e sua sustentação, posicionamento quanto a temas em discussão) e textos reivindicatórios: cartas de reclamação, petição (proposta, suas justificativas e ações a serem adotadas) e suas marcas linguísticas, de forma a incrementar a compreensão de textos pertencentes a esses gêneros e a possibilitar a produção de textos mais adequados e/ou fundamentados quando isso for requerido.

Fonte: Brasil (2018, p. 147).

Com base no que foi analisado, observamos que, além da preocupação do documento em descrever as competências e as habilidades que os alunos do Ensino Fundamental - Anos Finais devem ter para se tornarem sujeitos atuantes em práticas sociais de linguagem nos diversos contextos em que estão inseridos, ocorre, de fato, uma preocupação em reafirmar o posicionamento que a escola deve ter diante da conjuntura atual. Isso se dá reconhecendo a necessária inserção do texto em sala de aula nas práticas escolares sem, no entanto, subestimar os conhecimentos prévios do aluno.

Alertamos para o excesso de carga exigido ao longo do Ensino Básico, levando as escolas a compreenderem que devam obrigatoriamente trabalhar com todos os conteúdos citados na base. Advertimos também existe a possibilidade de que a quantidade de conteúdo sugerida pela BNCC impeça que os professores elaborem projetos de continuidade e de profundidade em um mesmo gênero, não apenas limitando o ensino ao estudo de estruturas e meios de divulgação de determinados gêneros, uma vez que é preciso que o professor leve os seus alunos a compreenderem o caráter sociodiscursivo, bem como o papel comunicativo que está atrelado à escrita dos diversos gêneros que circulam no meio social.

DOI: https://doi.org/10.32988/rep.v10n1.1279

Dossiê "Possibilidades de trabalho com a Língua Portuguesa"

\begin{tabular}{|l|l|l|l|l|l|l} 
Revista (Entre Parênteses) & Alfenas, MG & V.10 & n. 1 & $1-22$ & e021001 & 2021 \\
\hline
\end{tabular}




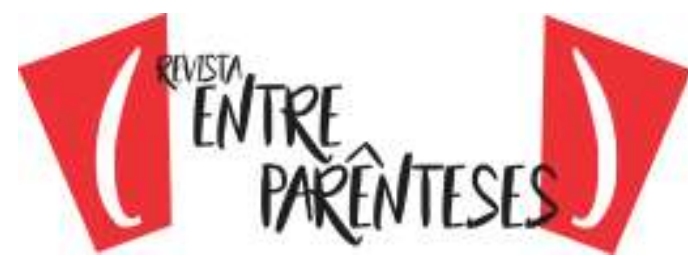

ISSN 2238-4502

Conforme Geraldi (2015), não existe motivo para ensinar na escola todos os gêneros de textos existentes e não se pode exigir que um leitor seja também autor de todos os tipos de texto que é capaz de ler. A leitura de diferentes gêneros, incluindo um texto jornalístico, não implica que necessariamente todos devam produzir textos na esfera jornalística.

Pereira e Koch (2014) expõem uma realidade de nossas escolas nas quais grande parte dos textos produzidos em sala de aula são escritos com a finalidade de cumprir um dever escolar. Assim, seria muito mais interessante que o aluno discutisse as informações veiculadas por um gênero específico, interagisse com os demais colegas e com o professor sobre determinado assunto para que possa, por exemplo, produzir um texto no qual convergem ações linguísticas, sociais e comunicativas, e não simplesmente como a sequência de palavras escritas ou organizadas especificamente para cumprir uma tarefa escolar.

\section{Considerações finais}

Ao longo do nosso estudo, compreendemos que a BNCC (componente Língua Portuguesa voltada para o Ensino Fundamental - Anos Finais) pretende prescrever a participação dos sujeitos em relação às práticas de linguagem em diferentes campos de atuação, principalmente nos novos contextos de uso de novas mídias, exagerando, muitas vezes, na quantidade de conteúdo a serem trabalhados.

Correntes linguísticas diversas apresentam perspectivas igualmente distintas para um mesmo objeto de estudo, haja vista a relação com a língua e com a linguagem a ser mediada pela concepção que se tem delas. Para tanto, nosso estudo voltou-se para o texto e para a Linguística de Texto, ao buscarmos compreender a materialidade textual em língua materna nesse documento tão recente que está sendo implementado em todas as escolas brasileiras. São vários os aspectos multiculturais que configuram um texto, já que o falante aciona uma complexa rede de fatores ao produzi-lo de forma escrita ou falada. Por isso, é fundamental o estudo apurado de qualquer documento normativo que tenha impacto significativo no currículo escolar.

Para tanto, ressaltamos a importância da efetivação de documentos oficiais mediante formações continuadas e a longo prazo, para que ocorram discussões para a implementação adequada dos componentes curriculares. Acreditamos que o componente Língua Portuguesa deve constituir-se como um espaço de promoção da leitura, de desenvolvimento das competências da compreensão/expressão oral e escrita, além de conhecimento reflexivo acerca da língua por meio do contato com uma variedade de textos e de situações que favoreçam o desenvolvimento intelectual, social e afetivo dos alunos, preparando-os com os instrumentos indispensáveis à participação ativa no mundo.

Nosso estudo não descarta a necessidade de análises mais profundas quanto ao que propõe a BNCC, dada a sua complexidade, tampouco pretende encerrar o longo debate que tem

DOI: https://doi.org/10.32988/rep.v10n1.1279

Dossiê "Possibilidades de trabalho com a Língua Portuguesa"

\begin{tabular}{|l|l|l|l|l|l|l|} 
Revista (Entre Parênteses) & Alfenas, MG & V. 10 & n. 1 & $1-22$ & e021001 & 2021 \\
\hline
\end{tabular}


circundado o documento desde a sua elaboração, especialmente no que se refere à aplicação dos conceitos aqui analisados, considerando os históricos problemas do ensino da língua materna em um país de grandes dimensões como o Brasil.

\section{Referências}

ANTUNES, I. Língua, gêneros textuais e ensino: considerações teóricas e implicações pedagógicas. Perspectiva: revista do Centro de Ciência da Educação, Florianópolis, v. 20, n. 1, p. 23-48, jan./jun. 2002.

BAKHTIN, M. Estética da criação verbal. Tradução de Paulo Bezerra. 4. ed. São Paulo: Martins Fontes, 2003.

BRAIT, B. 0 texto nas reflexões de Bakhtin e do Círculo. In: BATISTA, R. O. (org.). 0 texto e seus conceitos. São Paulo: Parábola Editorial, 2016. p. 13-30.

BRANDÃO, A. C. P. A revisão textual na sala de aula: reflexões e possibilidade de ensino. In: BRANDÃO, A. C. P.; LEAL, T. F. (org.). Produção de textos na escola: reflexões e práticas no ensino fundamental. Belo Horizonte: Autêntica, 2007.

BRASIL. Ministério da Educação. Base Nacional Comum Curricular: versão final. Brasília: Ministério da Educação, 2018. Disponível em:

http://basenacionalcomum.mec.gov.br/images/BNCCpublicacao.pdf. Acesso em: 5 set. 2020.

BENTES, A. C.; REZENDE, R. Texto: conceito, questões e fronteiras [com]textuais. In:

SIGNORINI, I. (org.). [Re]Discutir texto, gênero e discurso. São Paulo: Parábola Editorial, 2008. p. 19-46.

COLOMER, T. A formação do leitor literário: narrativa infantil e juvenil atual. Tradução de Laura Sandroni. São Paulo: Global, 2003.

CORRÊA, A.; MORGADO, J. C. A construção da Base Nacional Comum Curricular no Brasil: tensões e desafios. In: Colóquio Luso-brasileiro De Educação, 4., 2018, Braga; Paredes de Coura. Anais... UDESC; UMinho; UFMA, 2018. v. 3, p. 1-12.

CUNHA, E. V. R.; LOPEZ, A. C. Base nacional comum curricular no Brasil: regularidade na dispersão. Revista Investigación Cualitativa, v. 2, n. 2, p. 23-35, 2017. Disponível em: http://abrapecnet.org.br/wordpress/wp-content/uploads/2018/05/CunhaLopes2017.pdf. Acesso em: 12 jan. 2021.

DOI: https://doi.org/10.32988/rep.v10n1.1279

Dossiê "Possibilidades de trabalho com a Língua Portuguesa"

\begin{tabular}{|l|l|l|l|l|l|l} 
Revista (Entre Parênteses) & Alfenas, MG & V.10 & n. 1 & $1-22$ & e021001 & 2021 \\
\hline
\end{tabular}




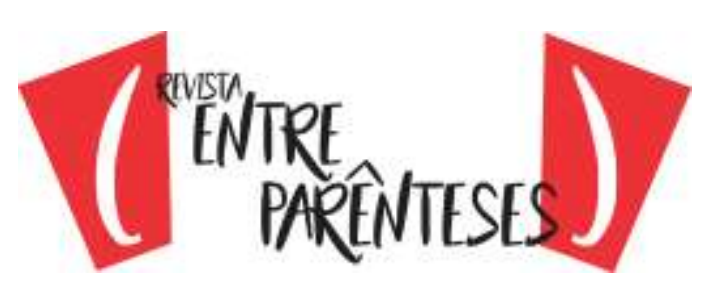

ISSN 2238-4502

ROJO, R. H. R.; BARBOSA, J. Hipermodernidade, multiletramentos e gêneros discursivos. São Paulo: Parábola Editorial, 2015.

SANTOS, C. F. 0 ensino da língua escrita na escola: dos tipos aos gêneros textuais. In: SANTOS, C. F; MENDONÇA, M.; CAVALCANTI, M. C. B. (org.). Diversidade textual: os gêneros na sala de aula. Belo Horizonte: Autêntica, 2007.

Recebido em 20/07/2020

Aceito em 07/10/2020

Publicado em 30/06/2021

DOI: https://doi.org/10.32988/rep.v10n1.1279

Dossiê "Possibilidades de trabalho com a Língua Portuguesa"

V. 10

n. 1




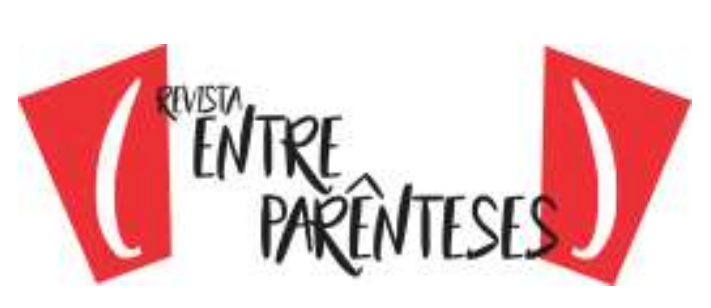

ISSN 2238-4502

\title{
THE PRESENCE OF TEXT IN THE CLASSROOM: AN ANALYSIS OF THE NATIONAL COMMON CURRICULAR BASE FROM THE PERSPECTIVE OF TEXTUAL LANGUAGE
}

\author{
Sammya Santos Araújo \\ Universidade do Porto \\ (sammyaletras@hotmail.com) \\ Lya Oliveira da Silva Souza Parente \\ Universidade Estadual do Ceará \\ (lya.loss@gmail.com)
}

\begin{abstract}
This article seeks to reflect, in the light of Textual Linguistics, the assumptions of the National Curricular Common Base (BNCC) in the Portuguese Language component. We try to understand what perspectives this normative document suggests for the text approach in Elementary Education. Methodologically, we conducted an exploratory and descriptive analysis of the specific skills and abilities that demand the use of text in the teaching and learning process. We understand that BNCC highlights the text as its object of study from the enunciative-discursive perspectives in a way that relates the texts to their production contexts and the development of skills to the significant use of language.
\end{abstract}

Keywords: Text. Text linguistics. Teaching. BNCC.

DOI: https://doi.org/10.32988/rep.v10n1.1279

Dossiê "Possibilidades de trabalho com a Língua Portuguesa"

\begin{tabular}{|l|c|c|c|c|c|c|}
\hline Revista (Entre Parênteses) & Alfenas, MG & V. 10 & n. 1 & $1-22$ & e021001 & 2021 \\
\hline
\end{tabular}


